Fifth International Conference on Sustainable Construction Materials and

Technologies. http://www.claisse.info/Proceedings.htm

\title{
THE USE OF ELECTRIC ARC FURNACE SLAG IN BITUMINOUS PAVEMENTS
}

Marta Skaf $^{1}$, Juan Manuel Manso ${ }^{2}$, José Antonio Chica ${ }^{3}$, Amaia Santamaría ${ }^{4}$, Emiliano Pasquini ${ }^{5}$ and Vanesa Ortega-López ${ }^{2}$.

${ }^{1}$ Affiliation: Department of Construction. University of Burgos. Spain Address: Escuela Politécnica Superior. Calle Villadiego s/n. 09001 Burgos. Spain. Email: mskaf@ubu.es.

${ }^{2}$ Affiliation: Department of Civil Engineering. University of Burgos. Spain Address: Escuela Politécnica Superior. Calle Villadiego s/n. 09001 Burgos. Spain. Email: jmmanso@ubu.es; vortega@ubu.es

${ }^{3}$ Affiliation: Sustainable Construction Division. Fundación Tecnalia Research \& Innovation Address: TECNALIA. Parque Tecnológico de Bizkaia C/Geldo, Edificio 700E48160 Derio. Bizkaia. Spain.

Email: joseantonio.chica@ tecnalia.com

${ }^{4}$ Affiliation: Department of Mechanical Engineering. University of the Basque Country, UPV/EHU. Spain

Address: Escuela de Ingeniería de Bilbao, I (bloque B) - UPV/EHU. Plaza Ingeniero Torres Quevedo, 1. 48013 Bilbao. Spain.

Email: amaia.santamaria@ehu.es

${ }^{5}$ Affiliation: Department of Civil, Environmental and Architectural Engineering (ICEA), University of Padua, Italy.

Address: University of Padua. Via Marzolo, 9. 35131 Padua, Italy.

Email: emiliano.pasquini@unipd.it

\section{ABSTRACT}

Electric Arc Furnace (EAF) slag, a waste stream in the production of carbon steel, has interesting and extensively researched mechanical properties as an aggregate in asphalt mixes. In this paper, an exhaustive review is conducted of its main features, the problematic aspects of its use, and the main properties of the mixes prepared with this aggregate, such as mechanical behaviour, resistance to fatigue and permanent deformation, water sensitivity and skid resistance.

Based on the literature review and own experience, the conclusion is that the use of EAF slag is generally recommended in partial replacement of the coarse aggregate, in all types of asphalt mixtures, following suitable pre-treatment. This usage improves mechanical performance, durability and long-term sustainability of the bituminous mixtures. Moreover, resistance against slipping and skidding on EAF slag pavements is an important safety-related aspect that makes them especially suitable for rainy regions. 
Keywords: Bituminous pavement, electric arc furnace, slag, fatigue, coarse aggregate

\section{ELECTRIC ARC FURNACE SLAG (EAFS)}

\subsection{Introduction}

EAF slag is the main waste stream in the secondary metallurgy phase, with production levels of about $120-170 \mathrm{~kg}$. per ton of steel.

There is extensive research into EAF oxidizing slag applications for the production of construction materials, the most common uses of which are as follows:

1. In embankments and platforms of roads and railways as an unbound material (Behiry, 2013; Chesner et al., 1998; Stroup-Gardiner and Wattenberg-Komas, 2013). The positive features of these slags as coarse aggregate are for granular layers on account of their strength, wear resistance and angularity. Their disadvantages are on the whole related to potential leaching and swelling.

2. In road pavements, as a quality aggregate for asphalt mixtures (Ali et al., 1992; Chesner et al., 1998; Emery, 1984; Stroup-Gardiner and Wattenberg-Komas, 2013). It is also a useful material for wearing courses, due to its high Polished Stone Values (PSV) and low Los Angeles coefficients (LA).

\subsection{Physical and Mechanical Properties}

EAF slag composition and properties depend on the steel production plant and it should be remarked that they can vary. Its resultant physical and chemical composition is influenced by: raw materials (origin and types of scrap, additions...), varied factory practices, final products (carbon steels, alloy steels, stainless steels...) and slag treatments (stabilization, dumping, and weathering).

The most notable mechanical and physical properties of EAF slag are:

- A clean hardened aggregate, limited volumes of fine material, and a high Sand Equivalent (SA) are all worth mentioning as well as the high angularity of this coarse aggregate, its rough texture and low flakiness index.

- It has a high density ( 3.2 to $\left.3.8 \mathrm{~g} / \mathrm{cm}^{3}\right)$, compared with standard aggregates (2.5$3.0 \mathrm{~g} / \mathrm{cm}^{3}$ ), a higher porosity and a higher water (and bitumen) absorption in comparison with natural aggregates.

- It is very cohesive, non-friable tough aggregate, in terms of its low Los Angeles abrasion coefficient that is usually resistant to disintegration, although dispersion has been observed, depending on the slag cooling and crushing procedure; Sofilić et al. (2010a) noted differences in the LA of water-cooled and air-cooled slag, with values of 13 and 16, respectively. Fonseca et al. (2013) examined slow cooling in a cone, noting LA values between 12 and 20, while pool poured slags usually showed LA values ranging from 18 to 25 .

- Reliable microtexture and frictional properties: high Polishing Stone Value (PSV), generally above 50 , not dissimilar to higher quality wearing course aggregates. Its lower aggregate abrasion values (AAV) were also found to demonstrate superior friction resistance.

- Solid adhesion with conventional bitumen is due to its basicity and chemical composition. 


\subsection{Problems in the Use of EAF Slag}

A central problem in reusing steel slag is uncertain volumetric stability. Free lime and periclase in hydration reactions mainly cause the expansion of EAF slag (Frías Rojas et al., 2002). A series of limit values are therefore defined in the majority of standards to control the expansive components of EAF slags, as well as thresholds on the values resulted from different expansion tests performed on the material, depending on the intended usage.

In contrast, the low amounts of toxic elements in steel slag mean that the properties of any water close to this material has to be carefully controlled (Sante et al., 2013). Heavy metal levels of EAF slag can be significant, but the percentage leaching is usually low (Proctor et al., 2000). In most standards, a leaching test on the granular material is prescribed, with strict thresholds for the toxic substances that it presents after elution.

\section{ASPHALT MIXTURES WITH EAF SLAG}

\subsection{Uses}

Most literature works on the application of EAF slag in bituminous mixtures refer to either partial or total coarse aggregate substitutions. As previously described, its mechanical characteristics mean that it is a very appropriate additional material, due to its angularity, hardness, roughness, and polishing resistance.

Bagampadde et al. (1999) noted reliable performance in mixtures with EAF slag as coarse aggregate and limestone as fine aggregate and filler, although the behaviour of mixtures exclusively made with steel slag was "inappropriate", worsening after submergence and showing unacceptable fatigue behavior. Bitumen adhesion was noticeably improved in mixes with limestone as fine aggregate and filler. Experimentation with slurries also showed good behavior if slag was the only coarse aggregate coupled with limestone fines (Khan and Al-Abdul Wahhab, 1998).

Ziari and Khabiri (2007) reported a substantial decline in quality with increased volumes of slag as fine replacement, recommending substitution levels below $50 \%$ of fine aggregate. Ziari et al. (2015) also concluded that a quality performance was possible with blended mixtures containing $50 \%$ steel slag in their fine, coarse or whole aggregate, balancing disproportionate air voids and excessive stiffness.

Asi et al. (2007) demonstrated that steel slag aggregates with as much as $75 \%$ of the coarse fraction improved asphalt concrete behaviour, although the most reliable performance was achieved with a coarse fraction content of $25 \%$ slag.

The best dynamic performance of Hot Mix Asphalt (HMA) (Arabani and Azarhoosh, 2012) and Stone Mastic Asphalt (SMA) (Behnood and Ameri, 2012) incorporated the slag only as coarse aggregate. The use of EAF slag fines has been rejected for warm mixes and water sensitivity in HMA was greatly worsened. Optimal moisture resistance appeared with slag as coarse aggregate and limestone as fines (Hesami et al., 2014; Oluwasola et al., 2015a, b).

The expensive crushing procedures of EAF slag may also be noted that is on the whole a coarse material, so its drawbacks as a fine aggregate are mainly economic rather than technical (Fonseca et al., 2013; Wang et al., 2013). 


\subsection{Pre-treatment and Stabilization}

Having removed all production process impurities, the slag undergoes aging, which propiciates the hydration of free lime and magnesia. This stabilization process is crucial in the manufacture of quality aggregates for asphalt mixtures production.

Uniform and consistent behaviour over time can be achieved through straightforward economic treatments (Skaf et al., 2017):

- Crushing, grinding and milling down to functional sizes, in accordance with the desired usage.

- Magnetic separation of a high proportion of metallic iron particles.

- Irrigation of the slag deposited in a pool, with a sprinkler system for hydration of its components over approximately 60 days.

- Slag-heap raking and turning for efficient weathering of its components.

\subsection{Mix Design}

The specific aspects of bituminous mixtures in combination with steel slag aggregate are as follows:

- A design with volumetric dosifications, on account of the relevant differences with standard aggregates in the apparent density of the material.

- The bulk density of asphalt mixes with EAF slag aggregates is $15-20 \%$ higher than conventional mixtures, on account of the high specific gravity of the slag.

- Slag mixtures usually show higher void contents, because of their the high angularity of their particles, which generates higher voids in the mineral aggregate.

- EAF slags have porous surfaces, which means higher absorption levels, requiring increased binder content.

\subsection{Manufacturing and Laying}

Transport costs should be calculated with the higher density of these mixtures in mind (Hunt and Boyle, 2000).

Lengthier heating periods of the aggregates may be necessary in the manufacturing process of asphalt mixes with steel slag, for total evaporation of all moisture, given the slag porosity levels (Chesner et al., 1998; Hunt and Boyle, 2000). The higher thermal inertia of the asphalt must also be considered following laying and pavement curing and hardening will take longer, before the resurfaced road can carry traffic, as heat is retained longer than usual (Hunt and Boyle, 2000) .

Some studies report that high percentages of steel slag aggregates cause problems due to their angularity, causing poor compactaction and increased void contents (Oluwasola et al., 2015a). The recommendations of the Federal Highway Administration of the US refer to slags used either in the coarse or in the fine fraction, or a mixture of both slag fractions with less angular aggregates to facilitate compaction (Chesner et al., 1998). This compaction issues can be reduced by increasing the binder content (Pasetto and Baldo, 2011), however using high amounts of slag with the binder percentage that produces optimal void content can cause bitumen draindown (Kandhal and Hoffman, 1982). A situation that impairs EAF slag mixture workability, even though used only in the coarse fraction (Pasetto and Baldo, 2012).

Regarding regularity, a study of Spanish highways involved regular three-month tests of EAF slag pavement surfaces throughout two years, yielding similar results to the 
standard mixtures (Fonseca et al., 2013). Surface regularity in a test section of permeable pavements with EAF slag (International Roughness Index, IRI $<2 \mathrm{~mm}$ ) also had positive results (Fang et al., 2013). Finally, a five year study of IRI after construction yielded similar results for both the standard and the steelmaking mixtures (Hunt and Boyle, 2000).

\subsection{Performance of Slag Mixes}

\subsubsection{Mechanical Behaviour}

Many studies have described the mechanical behaviour of mixes with steel slags in terms of enhanced stability, indirect tensile strength, stiffness, resilience, cracking, etc. (Ahmedzade and Sengoz, 2009; Ali et al., 1992; Ameri et al., 2013; Amuchi et al., 2015; Arabani and Azarhoosh, 2012; Asi et al., 2007; Li et al., 2015; Sofilić et al., 2010b; Sorlini et al., 2012).

High angularity, shear strength and resistance to polishing of slag particles, can result in better resistance to permanent deformation and can compensate potential cracking. The slag particles form stiffer mixtures, with superior stability and increased resilient moduli (Emery, 1984).

Pasetto and Baldo, in their studies with EAF slag, reported slag mixtures with high Marshall Stability and Marshall Quotient (MQ). The values were increased, especially at higher temperatures, with higher percentage substitutions of slag aggregate, and higher stiffness moduli (Pasetto and Baldo, 2010, 2011, 2012, 2014).

Slag mixes presented much higher resilient moduli, sometimes doubling conventional values, which was explained by the roughness of the steel slag but also by the higher binder content of those mixes, thereby improving their resilience (Hainin et al., 2013; Hainin et al., 2014; Hainin et al., 2012). Hamzah and Yi (2008) also reflected that finding in so far as they found that mixes with $100 \%$ EAF slag were less susceptibility to aging, due to better binder adhesion.

Higher slag contents meant higher Marshall stability and MQ values, because of the rougher surface and increased angulosity of the slag compared with the limestone aggregates (Kavussi et al., 2016; Kavussi and Qazizadeh, 2014). Likewise, Ziari et al. (2015) found that steel slag increased Marshall stability, decreased flow and improved ITS and MR.

Oluwasola et al. (2015a) found that the mixes with EAF slag showed the greatest stability, the lowest flow and better MQ and tensile strength values, better aggregate interlock and stronger resistance to high loads and shear stress. EAF slag use increased the resilient moduli and the differences were higher at higher temperatures, because binder adhesion was better.

Finally, steel slag pavement abrasion resistance was higher, as stated by $\mathrm{Li}$ et al. (2015), who found that the Cantabro wear loss met the requirements for permeable courses. Wen et al. (2016) also proposed taking advantage of the steel slag hard aggregates, to mitigate studded tire wear.

\subsubsection{Fatigue Resistance}

Bagampadde et al. (1999) observed worse results for slag samples in fatigue testing and this effect was increased with the limestone substitution percentage. 
Asi et al. (2007) established that the fatigue life of slag mixtures could be significantly improved, after cyclic ITS tests with a constant strain level. Arabani and Azarhoosh (2012) conducted indirect tensile fatigue tests, stating that steel slag coarse aggregate mixes also yielded the best fatigue life.

In various investigations, Pasetto and Baldo demonstrated lower fatigue compared to limestone mixtures, improved fatigue life and delayed macro-crack initiation (Pasetto and Baldo, 2010, 2011, 2012).

Kavussi and Qazizadeh found that mixes containing steel slag had a longer fatigue life, in accordance with several methods, based on four-point bending fatigue tests (Kavussi et al., 2016; Kavussi and Qazizadeh, 2014).

Ziari et al. (2015) showed that the fatigue life of steel slag mixtures was higher when the EAF slag was used either as the coarse or the fine fraction, but their results were unacceptable in the four-point beam fatigue tests on $100 \%$ slag mixtures.

Wen et al. (2016) showed that top-down fatigue cracking resistance was unaffected in slag mixes with the addition of up to $60 \%$ of the aggregate.

\subsubsection{Resistance to Permanent Deformation}

A range of studies have shown higher slag mix resistance to permanent deformations as a result of creep stiffness and rutting (Ahmedzade and Sengoz, 2009; Ali et al., 1992; Ameri et al., 2013; Amuchi et al., 2015; Behnood and Ameri, 2012; Li et al., 2015; Pasetto and Baldo, 2011, 2012, 2014; Pasetto et al., 2017; Wen et al., 2016; Wu et al., 2007). Their results were explained by the coarse aggregate properties, particularly high angularity, hardness, shear strength, resistance to wear and polishing of the slag particles.

Such high levels of resistance to creep and rutting in pavements mean that they are very suitable for roads with heavy traffic flows and parking areas for heavy vehicles (Emery, 1984; Hainin et al., 2013; Hainin et al., 2014)

Sofilić et al. (2010b) showed that wheel-tracking slope and rut depth in sections with $70 \%$ EAF slag were considerably improved. Wang and Wang (2011) also demonstrated that rut depths in porous EAFS mixes were one third less than in granite mixtures.

Permanent deformation studied by dynamic creep tests applied to SMA (Behnood and Ameri, 2012), HMA (Arabani and Azarhoosh, 2012) and WMA (Ameri et al., 2013) demonstrated that the coarse fraction of steel slag mixes had greater resistance to permanent deformation and lower rut depths.

Hanin et al. studied both SMA and HMA, as well as porous mixtures, finding better performance of slag mixtures in creep tests and better and longer-lasting resistance to deformations. In addition, the rut depths of the slag mixtures were half or even in some cases a third lower than the reference specimen, due to higher angularity and friction of the steelmaking aggregates (Hainin et al., 2013; Hainin et al., 2014; Hainin et al., 2012).

Dynamic creep tests (Oluwasola et al., 2015a) and wheel rutting (Oluwasola et al., $2015 \mathrm{~b}$ ) used to measure permanent deformation, were demonstrably improved in the slag mixtures, due to the EAFS angularity and higher resistance to friction and abrasion. 


\subsubsection{Moisture Sensitivity}

Slag mixtures water sensitivity varied in the bibliographic works that were consulted. The substitution ratio and the particle size of the slag seem to determine its performance, as well as the binder chosen and the aggregate used as reference.

Similar performances were established for the moisture susceptibility of the slag mixes, as in Sofilić et al. (2010b), Wang and Wang (2011) and Wen et al. (2016).

Various studies found that when using EAFS both as coarse and fine aggregate, the samples resulted in higher dry and wet ITS and better TSR (Pasetto and Baldo, 2010, 2011, 2012, 2014). This was explained by the higher binder content of the slag mixtures.

According to Ahmedzade and Sengoz (2009), slag mixtures were more cohesive, which was reflected in higher Indirect Tensile Strength Ratio (ITSR) compared to limestone mixtures; Behnood and Ameri (2012) suggested that steel slag in the coarse portion could lessen moisture damage in SMA mixtures.

Hesami et al. (2014) in a complete study on bituminous mixes with slag aggregates and their moisture susceptibility, demonstrated that slag used as sand degraded the water sensitivity. Similar results were found by Pasetto et al. (2016). Conversely, the moisture resistance of coarse aggregate slag mixtures was very high (Ameri et al., 2013; Hesami et al., 2014). Their understanding was that they had lower alkalinity than limestone and worse binder affinity, but conversely, the slag porosity and roughness, as the higher bitumen content led to a better bitumen coated particles (Hesami et al., 2014).

In a separate study, modified bitumen affinity with EAFS as the coarse aggregate showed enhanced adhesion and moisture resistance of Warm Mix Asphalt (Ameri et al., 2013; Hesami et al., 2014).

\subsubsection{Skid Resistance}

The EAF slag has a high PSV that means very good polishing resistance, which explains the higher skid resistance than standard values in tests on these type of pavements (Stock et al., 1996). These results reinforce the use of slags in wearing courses in heavy road traffic (Emery, 1984).

Both laboratory and full-scale experiments support the above conclusions. The central one is that slag pavements offer better skid resistance (Asi, 2007; Hunt and Boyle, 2000; Sofilić et al., 2010b), as well as other remarks of interest:

- The British Pendulum Number (BPN) progression over time in slag mixtures was consistently better than conventional aggregates (Li et al., 2007) and so was the skid resistance measured through the Sideways-Force Coefficient Routine Investigation Machine (SCRIM) (Stock et al., 1996).

- Macro and microtexture of surfaces two years after laying for SMA pavements showed encouraging results and a good evolution (Wu et al., 2007). Similar results were found for skid resistance and macrotexture evolution in HMA used in Greek highways (Kehagia, 2009; Liapis and Likoydis, 2012)

- Steel slag pavements had the highest BPN and mean texture depth in laboratory tests. This was attributed to the angular shape of the particles, their high density and surface texture, which all reduced degradation and added to road surface resistance (Oluwasola et al., 2015b). 


\subsubsection{Mixture Expansion}

The first road sections with steel slag had problems of volumetric instability as the slag had not been properly weathered (Ciesielski, 1996; Coomarasamy and Walzak, 1995). The swelling was more significant when using BOF slag, while the problems of some sections with EAF slag might be explained by inappropiate mixing with Ladle Furnace (LF) slag (Fonseca et al., 2013) and a majority of authors stressed the safety of properly stabilized EAF slag in bituminous mixtures.

Reagarding laboratory expansivity tests on asphalt mixes, they showed no swelling after freeze-thaw cycles and hot baths (Kandhal and Hoffman, 1997) and in studies with $100 \%$ of EAF slag specimens their expansion was $<1 \%$ by volume following immersion in hot baths at $60{ }^{\circ} \mathrm{C}$ for one week, (Kavussi and Qazizadeh, 2014).

In a full-scale pilot developed on Basque Country highways in Spain, no expansive phenomenon was shown after five years of monitoring following construction. The EAFS used was required to fulfil EN 1744- $1<5 \%, \mathrm{MgO}<10 \%$ and free $\mathrm{CaO}<0.5 \%$ (Fonseca et al., 2013).

\subsubsection{Leaching}

Milačič et al. (2011) subjected various HMA samples containing EAFS to different leaching tests, concluding that metals from the slag in bituminous mixtures were efficiently immobilized by bitumen. Scheibmeir et al. (2011) arrived at the same conclusions, suggesting that a minor fraction of leached elements were emitted by the slags enveloped in a bitumen matrix.

Most metals had a insignificant presence in leaching, except for vanadium and chromium, which were very low, showing no health risk (Milačič et al., 2011).

Sorlini et al. (2012) performed leaching tests on granular material and on bituminous mixes with different types of EAF slag, concluding that the bitumen samples leachate was much lower and the pollutants were well below regulatory levels. Chromium and vanadium were the most critical parameters.

\section{MAIN CONCLUSIONS}

\section{Strengths}

- The EAF slag presents very good mechanical properties (roughness, shape, angularity, hardness, polishing and wear resistance, etc.), meaning that it is appropriate to be used as a coarse aggregate in bituminous mixtures.

- Most authors supported the replacement of high rates of the coarse fraction with slag aggregates. In some cases, a total substitution of the coarse fraction can be suitable, although the optimal substitution rate was usually lower.

- Steel slag aggregate mixtures showed a mechanical behaviour that was usually better than the samples with conventional aggregates (stability, indirect tensile strength, creep, cracking, fatigue, permanent deformation, abrasion, etc.).

- Skid resistance and its evolution over time were usually very good, due to the high polishing resistance of the slag.

- The swelling and leaching tests on bituminous mixtures showed no problems. 


\section{Weaknesses}

- Slag is not recommended as fine aggregate and filler in most cases. Water sensitivity appeared to cause most of the problems. Additionally, the expense of crushing operations is usually prohibitive.

- Slag pre-treatment is invariably needed: removal of impurities, crushing and weathering to produce a stable and quality aggregate.

- In the mix design, a slight increase in binder content is advisable, given the high absorption levels of slag, to arrive at optimal levels. Slag transport costs will also be higher, given the higher densities and weight of these materials.

- Mixes with high percentages of slag tend to have more voids, and the optimum binder content can be excessive and lead to binder drainage problems. Both circumstances can cause compactability difficulties.

\section{ACKNOWLEDGMENTS.}

The authors wish to express their gratitude to the following bodies for their financial support of this research: Junta de Castilla y León (Regional Government) for funding UIC-231 through project BU119P17; Spanish Ministry (MICINN) and FEDER (European Regional Development Funds) and, finally, Basque Government research group (IT1314-19 and IT781-13).

\section{BIBLIOGRAPHY}

Ahmedzade, P., Sengoz, B., 2009. Evaluation of steel slag coarse aggregate in hot mix asphalt concrete. Journal of Hazardous Materials 165(1-3), 300-305. DOI: 10.1016/j.jhazmat.2008.09.105.

Ali, N.A., Chan, J.S.S., Papagiannakis, T., Theriault, E.G., Bergan, A.T., 1992. Use of steel slag in asphaltic concrete, in: Meininger Richard, C. (Ed.) Symposium on Effects of Aggregates and Mineral Fillers on Asphalt Mixture Performance, 1147 ed. Publ by ASTM, Philadelphia, PA, United States; San Diego, CA, USA, pp. 3-18.

Ameri, M., Hesami, S., Goli, H., 2013. Laboratory evaluation of warm mix asphalt mixtures containing electric arc furnace (EAF) steel slag. Construction and Building Materials 49, 611617. DOI: 10.1016/j.conbuildmat.2013.08.034.

Amuchi, M., Abtahi, S.M., Koosha, B., Hejazi, S.M., Sheikhzeinoddin, H., 2015. Reinforcement of steel-slag asphalt concrete using polypropylene fibers. J. Ind. Text. 44(4), 526-541. DOI: $10.1177 / 1528083713502998$.

Arabani, M., Azarhoosh, A.R., 2012. The effect of recycled concrete aggregate and steel slag on the dynamic properties of asphalt mixtures. Construction and Building Materials 35, 1-7. DOI: 10.1016/j.conbuildmat.2012.02.036.

Asi, I.M., 2007. Evaluating skid resistance of different asphalt concrete mixes. Building and Environment 42(1), 325-329. DOI: 10.1016/j.buildenv.2005.08.020. 
Asi, I.M., Qasrawi, H.Y., Shalabi, F.I., 2007. Use of steel slag aggregate in asphalt concrete mixes. Canadian Journal of Civil Engineering 34(8), 902-911. DOI: 10.1139/L07-025.

Bagampadde, U., Wahhab, H.I.A.-A., Aiban, S.A., 1999. Optimization of steel slag aggregates for bituminous mixes in Saudi Arabia. Journal of Materials in Civil Engineering 11(1), 30-35. DOI: 10.1061/(ASCE)0899-1561(1999)11:1(30).

Behiry, A.E.A.E.M., 2013. Evaluation of steel slag and crushed limestone mixtures as subbase material in flexible pavement. Ain Shams Engineering Journal 4(1), 43-53. DOI: 10.1016/j.asej.2012.07.006.

Behnood, A., Ameri, M., 2012. Experimental investigation of stone matrix asphalt mixtures containing steel slag. Scientia Iranica 19(5), 1214-1219. DOI: 10.1016/j.scient.2012.07.007.

Ciesielski, S.K., 1996. Case histories of solid waste industrial slags used in hot mix asphalt concrete pavements, Proceedings of the 1996 12th International Conference on Solid Waste Technology and Management. Univ of Pennsylvania, Philadelphia, PA, USA.

Coomarasamy, A., Walzak, T.L., 1995. Effects of moisture on surface chemistry of steel slags and steel slag-asphalt paving mixes. Transportation Research Record 1492, 85-95.

Chesner, W.H., Collins, R.J., MacKay, M., 1998. User Guidelines for Waste and Byproduct Materials in Pavement Construction. No. FHWA-RD-97-148. U.S. Department of Transportation. Federal Highway Administration.

Emery, J.J., 1984. Steel Slag utilization in asphalt mixes, Canadian Technical Asphalt Association Proceedings. National Slag Association.

Fang, F.T., Chong, Y.C., Nyunt, T.T., Loi, S.S., 2013. Development of environmentally sustainable pavement mix. International Journal of Pavement Research and Technology 6(4), 440-446. DOI: 10.6135/ijprt.org.tw/2013.6(4).440.

Fonseca, A.I., Gascón, C., Ruiz De Ojeda, J.L., Navarro, J.A., Ruiz, A., 2013. Use of iron and steel aggregate in the Basque Country. Carreteras 4(187), 50-63.

Frías Rojas, M., Sánchez De Rojas, M.I., Uría, A., 2002. Study of the instability of black slags from electric arc furnace steel industry. Materiales de Construcción 52 (267), 79-83.

Hainin, M.R., Rusbintardjo, G., Abdul Aziz, M.A., Hamim, A., Md. Yusoff, N.I., 2013. Laboratory evaluation on steel slag as aggregate replacement in stone mastic asphalt mixtures. J. Teknol. 65(2), 13-19. DOI: 10.11113/jt.v65.2185.

Hainin, M.R., Rusbintardjo, G., Hameed, M.A.S., Hassan, N.A., Yusoff, N.I.M., 2014. Utilisation of steel slag as an aggregate replacement in porous asphalt mixtures. J. Teknol. 69(1), 67-73. DOI: $10.11113 /$ jt.v69.2529. 
Hainin, M.R., Yusoff, N.I.M., Sabri, M.F.M., Aziz, M.A.A., Hameed, M.A.S., Reshi, W.F., 2012. Steel Slag as an Aggregate Replacement in Malaysian Hot Mix Asphalt. ISRN Civil Engineering. DOI: $10.5402 / 2012 / 459016$.

Hamzah, M.O., Yi, T.C., 2008. Effects of Temperature on Resilient Modulus of Dense Asphalt Mixtures Incorporating Steel Slag Subjected to Short Term Oven Ageing. International Journal of Civil, Environmental, Structural, Construction and Architectural Engineering 2, 221-226.

Hesami, S., Ameri, M., Goli, H., Akbari, A., 2014. Laboratory investigation of moisture susceptibility of warm-mix asphalt mixtures containing steel slag aggregates. International Journal of Pavement Engineering 16(8), 745-759. DOI: 10.1080/10298436.2014.953502.

Hunt, L., Boyle, G., 2000. Steel slag in hot mix asphalt concrete. Final Report, Oregon Department of Transportation.

Kandhal, P.S., Hoffman, G.L., 1982. The use of steel slag as bituminous concrete fine aggregate. Pennsylvania Department of Transportation Research Project.

Kandhal, P.S., Hoffman, G.L., 1997. Evaluation of steel slag fine aggregate in hot-mix asphalt mixtures. Transportation Research Record, pp. 1583: 1528-1536.

Kavussi, A., Jalili Qazizadeh, M., Hassani, A., 2016. Fatigue Behavior Analysis of Asphalt Mixes Containing Electric Arc Furnace (EAF) Steel Slag. Journal of Rehabilitation in Civil Engineering 3(1), 74-86.

Kavussi, A., Qazizadeh, M.J., 2014. Fatigue characterization of asphalt mixes containing electric arc furnace (EAF) steel slag subjected to long term aging. Construction and Building Materials 72, 158-166. DOI: 10.1016/j.conbuildmat.2014.08.052.

Kehagia, F., 2009. Skid resistance performance of asphalt wearing courses with electric arc furnace slag aggregates. Waste Management and Research 27(3), 288-294. DOI: $10.1177 / 0734242 \times 08092025$.

Khan, M.I., Al-Abdul Wahhab, H.I., 1998. Improving slurry seal performance in Eastern Saudi Arabia using steel slag. Construction and Building Materials 12(4), 195-201. DOI: 10.1016/S0950-0618(98)00005-1.

Li, C., Xiang, X., Zhou, X., 2015. Investigation of performance of porous open graded steel slag asphalt mixture. Jianzhu Cailiao Xuebao/Journal of Building Materials 18(1), 168-171. DOI: 10.3969/j.issn.1007-9629.2015.01.030.

Li, S., Zhu, K., Noureldin, S., 2007. Evaluation of friction performance of coarse aggregates and hot-mix asphalt pavements. Journal of Testing and Evaluation 35(6), 571-577. DOI: https://doi.org/10.1520/JTE100903.

Liapis, I., Likoydis, S., 2012. Use of Electric Arc Furnace Slag in Thin Skid-Resistant Surfacing. Procedia - Social and Behavioral Sciences 48, 907-918. DOI: 10.1016/j.sbspro.2012.06.1068. 
Milačič, R., Zuliani, T., Oblak, T., Mladenovič, A., Ščančar, J., 2011. Environmental impacts of asphalt mixes with electric arc furnace steel slag. Journal of Environmental Quality 40(4), 1153-1161. DOI: 10.2134/jeq2010.0516.

Oluwasola, E.A., Hainin, M.R., Aziz, M.M.A., 2015a. Evaluation of asphalt mixtures incorporating electric arc furnace steel slag and copper mine tailings for road construction. Transp. Geotech. 2, 47-55. DOI: 10.1016/j.trgeo.2014.09.004.

Oluwasola, E.A., Hainin, M.R., Aziz, M.M.A., 2015b. Evaluation of rutting potential and skid resistance of hot mix asphalt incorporating electric arc furnace steel slag and copper mine tailing. Indian J. Eng. Mater. Sci. 22(5), 550-558.

Pasetto, M., Baldo, N., 2010. Experimental evaluation of high performance base course and road base asphalt concrete with electric arc furnace steel slags. Journal of Hazardous Materials 181(1-3), 938-948. DOI: 10.1016/j.jhazmat.2010.05.104.

Pasetto, M., Baldo, N., 2011. Mix design and performance analysis of asphalt concretes with electric arc furnace slag. Construction and Building Materials 25(8), 3458-3468. DOI: 10.1016/j.conbuildmat.2011.03.037.

Pasetto, M., Baldo, N., 2012. Performance comparative analysis of stone mastic asphalts with electric arc furnace steel slag: A laboratory evaluation. Materials and Structures 45(3), 411424. DOI: 10.1617/s11527-011-9773-2.

Pasetto, M., Baldo, N., 2014. Influence of the aggregate skeleton design method on the permanent deformation resistance of stone mastic asphalt. Mater. Res. Innov. 18(SUPPL. 3), S96-S101. DOI: 10.1179/1432891714Z.000000000588.

Pasetto, M., Baliello, A., Giacomello, G., Pasquini, E., 2017. Sustainable solutions for road pavements: A multi-scale characterization of warm mix asphalts containing steel slags. J. Clean. Prod. 166, 835-843. DOI: 10.1016/j.jclepro.2017.07.212.

Pasetto, M., Giacomello, G., Pasquini, E., Canestrari, F., 2016. Effect of warm mix chemical additives on the binder-aggregate bond strength and high-service temperature performance of asphalt mixes containing electric arc furnace steel slag, RILEM Bookseries. pp. 485-496. DOI: 10.1007/978-94-017-7342-3_39.

Proctor, D.M., Fehling, K.A., Shay, E.C., Wittenborn, J.L., J.J., G., Avent, C., 2000. Physical and chemical characteristics of blast furnace, basic oxygen furnace and electric arc furnace steel industry slag. Environmental Science and Technology 34(8), 1576-1582. DOI: 10.1021/es9906002.

Sante, L.D., Cirilli, F., Angelucci, N., 2013. EAF slag: A product no longer a problem. Iron and Steel Technology 10(5), 257-265.

Scheibmeir, E., Ortiz, J., Bou, M., 2011. Mezclas bituminosas de granulometría continua elaboradas enteramente con árido siderúrgico, VI Jornada Nacional de ASEFMA. 
Skaf, M., Manso, J.M., Aragón, Á., Fuente-Alonso, J.A., Ortega-López, V., 2017. EAF slag in asphalt mixes: A brief review of its possible re-use. Resources, Conservation and Recycling 120, 176-185. DOI: 10.1016/j.resconrec.2016.12.009.

Sofilić, T., Merle, V., Rastovčan-mioč, A., Ćosić, M., Sofilić, U., 2010a. Steel slag instead natural aggregate in asphalt mixture. Archives of Metallurgy and Materials 55(3), 657-668.

Sofilić, T., Rastovčan-Mioč, A., Ćosić, M., Merle, V., Mioč, B., Sofilić, U., 2010b. EAF steel slag application posibilities in Croatian asphalt mixture production, 4th International Conference on Safety and Environment in Process Industry, CISAP4. Florence, pp. 109-115. DOI: 10.3303/CET1019019.

Sorlini, S., Sanzeni, A., Rondi, L., 2012. Reuse of steel slag in bituminous paving mixtures. Journal of Hazardous Materials 209-210, 84-91. DOI: 10.1016/j.jhazmat.2011.12.066.

Stock, A.F., Ibberson, C.M., Taylor, I.F., 1996. Skidding characteristics of pavement surfaces incorporating steel slag aggregates, Transportation Research Record. pp. 35-40.

Stroup-Gardiner, M., Wattenberg-Komas, T., 2013. Slag Byproducts, Recycled Materials and Byproducts in Highway Applications. TRB's National Cooperative Highway Research Program (NCHRP). DOI: 10.17226/22548.

Wang, Q., Yang, J., Yan, P., 2013. Cementitious properties of super-fine steel slag. Powder Technology 245, 35-39. DOI: 10.1016/j.powtec.2013.04.016.

Wang, Y., Wang, G., 2011. Improvement of porous pavement, Final Report to US Green Building Council. East Carolina University, Greenville, NC.

Wen, H., Wu, S., Bhusal, S., 2016. Performance Evaluation of Asphalt Mixes Containing Steel Slag Aggregate as a Measure to Resist Studded Tire Wear. Journal of Materials in Civil Engineering 28(5), 04015191. DOI: 10.1061/(asce)mt.1943-5533.0001475.

Wu, S., Xue, Y., Ye, Q., Chen, Y., 2007. Utilization of steel slag as aggregates for stone mastic asphalt (SMA) mixtures. Building and Environment 42(7), 2580-2585. DOI: 10.1016/j.buildenv.2006.06.008.

Ziari, H., Khabiri, M.M., 2007. Preventive maintenance of flexible pavement and mechanical properties of steel slag asphalt. Journal of Environmental Engineering and Landscape Management 15(3), 188b-192b.

Ziari, H., Nowbakht, S., Rezaei, S., Mahboob, A., 2015. Laboratory Investigation of Fatigue Characteristics of Asphalt Mixtures with Steel Slag Aggregates. Adv. Mater. Sci. Eng. 2015. DOI: $10.1155 / 2015 / 623245$. 
